\title{
Fit for public consumption? An exploratory study of the reporting of nutrition research in UK tabloids with regard to its accuracy, and a preliminary investigation of public attitudes towards it
}

\author{
Andrea J Basu* and Elaine Hogard \\ School of Health and Social Care, University College Chester, Parkgate Road, Chester CH1 4BJ, UK
}

Submitted 23 February 2007: Accepted 24 October 2007: First published online 21 January 2008

\begin{abstract}
Objective: To explore the quality (accuracy, balance, practical context) of tabloid articles reporting on nutrition research, and public attitudes towards it.

Design: A qualitative multi-method study consisting of a systematic analysis of tabloid articles and a series of focus groups with members of the public.

Setting: Tabloid newspapers (nationwide). Focus groups were conducted at a UK university.

Subjects: All UK tabloid newspapers were collated for a full calendar month. Members of the local Women's Institute and non-teaching staff within the University College Chester were recruited as focus group participants.

Results: Twenty-nine tabloid articles were included. A standardised TAT (Tabloid Analysis Tool) was used a total of thirty-nine times (once for each research study cited). Twenty-six failed to accurately report research results, thirty-six failed to mention significant research limitations, and only five quoted a third-party expert source. Two focus groups, each with eight participants, were conducted. Attitudes expressed were largely negative, highlighting elements of confusion and scepticism. Articles were more likely to be disregarded than acted upon, although some value was attached to newspapers providing nutrition information.

Conclusions: Tabloid reporting on nutrition research is not sufficiently accurate, balanced or contextualised, and public attitudes towards the reporting are not wholly favourable. Guidance for journalists via registered dietitians and a strengthening of present links could serve to utilise this form of mass media more effectively.
\end{abstract}

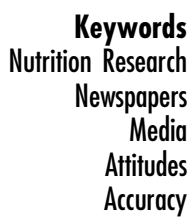

The public's desire for information on nutrition is increasing $^{(1)}$, yet we have little knowledge regarding public attitudes towards what information is presented by the media nor how accurate the reporting is in relation to the research to which it refers. Tabloid newspapers are a popular form of mass media within the UK. The public has quoted the print media as a key source of information on nutrition ${ }^{(2,3)}$. However, there is a lack of empirical research that has examined the quality of nutrition research reported in the media. For the purpose of this study, 'quality' of reporting is judged on whether the report concurs precisely with the original research study, if it remains unbiased not giving a misleading view of the research, and whether it provides practical contextual information for the public. The present qualitative study examined the quality of tabloid articles reporting on nutrition research, and public attitudes towards them.

\section{Literature review}

Tabloids account for $75 \%$ of all daily UK newspaper sales $^{(4)}$. A UK Food Standards Agency consumer survey ${ }^{(5)}$ and a European study ${ }^{(3)}$ stated that the public identified the media (press) within its top two sources of information on food and healthy eating. Bubela and Caulfield's research $^{(6)}$ concluded that the media provides an accurate reflection of what is conveyed by the research community, whereas Henderson et $a l .{ }^{(7)}$ and Philo et al. ${ }^{(8)}$ suggested that the media can be inaccurate. Stryker ${ }^{(9)}$ stated that inaccuracies resulting from the decontextualised and sensationalised manner in which stories are reported are conceptually distinct from, and occur with greater frequency than, actual errors contained within the story'. McBean ${ }^{(10)}$ and Wellman et $a l^{(11)}$ proposed that newspapers favour reporting preliminary research which, 
without supplementary explanation, can oversimplify/ overstate inconclusive findings. Guidelines on communicating scientific findings state it is vital to convey that research is evolutionary and not revolutionary, i.e. highlight where a single study falls on the research continuum $^{(12)}$. Including the expert opinion of a third party is recommended to support journalistic balance when reporting research ${ }^{(13)}$.

Borra et al. ${ }^{(14)}$ concluded that 'most nutrition news failed to provide contextual information'. McBean ${ }^{(10)}$ argued that a lack of context is largely responsible for the public's confusion over what they should eat. Registered dietitians are equipped to interpret emerging nutrition research for the media ${ }^{(1)}$. Possible inaccuracies and insufficient practical context questions the value of nutrition information via the print media in terms of health literacy, i.e. the capacity of individuals to obtain, interpret and understand health information in ways that are health-enhancing ${ }^{(15)}$.

There is a lack of information regarding the public's attitude towards nutrition information featured by the print media. Attitudes are constructed via three components: cognitive, affective and conative ${ }^{(16)}$. Briefly, these components cover thoughts regarding an object, feelings towards the object, and disposition to action regarding the object. With regard to the cognitive component, views within the literature ${ }^{(10,17,18)}$ suggest the public is commonly confused by health-related information conveyed by the media. For the affective component, a consumer survey ${ }^{(19)}$ found that $75 \%$ of respondents reported that sensationalism in the media affected their trust in the news. Distrust might be linked to the public's unfamiliarity with the scientific process ${ }^{(10)}$. Frewer et al. ${ }^{(20)}$ suggested that an individual's attitude towards a topic, prior to reading a report, will also influence trust and opinion. In respect of conation, Russell ${ }^{(21)}$ suggested that attitudes might be considered a poor predictor of behaviour, but Goldberg ${ }^{(22)}$ believed media influences to have largely contributed towards some changes in public food consumption patterns.

US guidance on cascading nutrition research to the public was issued in $1998^{(23)}$, updated in $2005^{(12)}$. Currently the UK has no guidance documentation in place.

\section{Design and methods}

Two research questions were addressed in the present study:

1. How accurately do tabloid newspapers report scientific findings on nutrition?

2. What are the attitudes of a key readership group to tabloid reporting of scientific findings on nutrition?

These questions were addressed through two studies. The first comprised a systematic analysis of tabloid newspaper clippings to determine the accuracy of reporting and the second involved focus group discussions held with members of the general public who were presented with original tabloid articles to assess their attitudes to this reporting.

Tabloid reporting of scientific nutrition research articles was assessed for accuracy using a specially devised tool, the Tabloid Analysis Tool (TAT) (see Appendix). No existing tools were fit for the purpose of assessing the accuracy, balance and contextual information of tabloid reporting of nutrition research articles. A tool devised by Hackman and $\mathrm{Moe}^{(24)}$, and guidance issued by the Harvard School of Public Health and the International Food Information Council (IFIC) ${ }^{(22)}$ and the IFIC and the Institute of Food Technologists (IFT) ${ }^{(12)}$, provided some direction on elements for inclusion.

The TAT was devised to conduct the systematic analysis of tabloid articles. Questions were specifically targeted at determining whether tabloid reports were accurate (with respect to original research), maintained journalistic balance, and contained sufficient practical dietary context. A standard instrument was preferred to facilitate a systematic, unbiased approach to the analysis. Tabloid articles and their related research papers were read fully, and then assessed individually using the TAT tool. The TAT was piloted on ten test articles prior to the main study and was trialled by two impartial parties (registered dietitians) to ensure reliability and validity.

Focus groups are accepted as an appropriate qualitative measure for collecting attitudinal data ${ }^{(25,26)}$ and the groups were planned and conducted according to best practice guidelines ${ }^{(27)}$. Two tabloid articles were selected for the focus group sessions. These gave examples of very poor and the least poor in terms of reporting quality (determined by TAT assessment). Focus group participants were not informed of the origins of the articles. Following a welcome and introduction, participants were presented with the tabloid articles in turn, and were asked three standard questions for each: (i) If you were to tell a friend/relative about the article, how would you describe its contents? (ii) What do you think of the article? (iii) Would you consider acting upon the advice/following the information? Focus group sessions were conducted over one hour.

\section{Sampling}

All UK tabloids ('red tops', i.e. The Sun, Daily Mirror and Daily Star, and 'mid-markets', i.e. Daily Mail and Daily Express) were sampled over a full calendar month (January 2005) and scanned for reporting of nutrition research. Tabloids were selected owing to their wide readership and mass appeal ${ }^{(4,6)}$.

For the focus groups, participants were recruited via a purposeful and convenient sampling using the inclusion criteria of adult, willing to participate, non-specialists in food/nutrition, and likely to purchase a tabloid newspaper, 
given readership characteristics ${ }^{(4)}$. Readership characteristics show that mid-market tabloids are read predominantly by women ${ }^{(28)}$. A quarter of Daily Mail and a third of Daily Express readers are aged 65 years or over $^{(29)}$. Therefore a key group approached for inclusion was the Women's Institute, where both characteristics would be present.

\section{Data collection}

Newspapers were purchased and examined daily for the period January 2005. Articles reporting on nutrition research and providing a traceable source to the original research (journal name, author and/or organisation) were clipped. Where the original research could not be obtained, reports were excluded from the study.

A questioning guide was used within the focus groups to elicit attitudes towards the tabloid articles presented. Participants were allocated time to read articles, and were asked three open-ended questions to generate discussion. An assistant moderator made contemporaneous notes. Focus group data were audio-recorded with digital equipment, and computer software was used to download the data for transcribing purposes. Participants were informed of the audio recording prior to the sessions, and were assured that data would be anonymous and dealt with confidentially.

\section{Analysis}

Tabloid articles were assessed individually by the principal researcher (a registered dietitian) using the TAT. The TAT was used once for every reference made to a piece of research. Data were recorded sequentially on an Excel spreadsheet, and were analysed question-by-question or grouped in order to address one of the three specific parameters (accuracy, balance and context). Focus group data were analysed using a transcript-based method that is accepted as the most rigorous method ${ }^{(30)}$. A 'long table approach'(27) was selected to identify emerging themes.

\section{Results}

Thirty-two tabloid articles formed the original study sample; twenty-nine met the inclusion criteria for the study. A number of articles referred to more than one nutrition research study and therefore the TAT was used a total of thirty-nine times, once for each reference made to a locatable research study. Figure 1 shows the number of occasions that the TAT was used throughout the study stratified according to origin.

\section{Accuracy}

Twenty-six articles did not accurately convey the original research results. Fourteen reported the study's sample size but only five did so accurately. Twenty-seven articles used

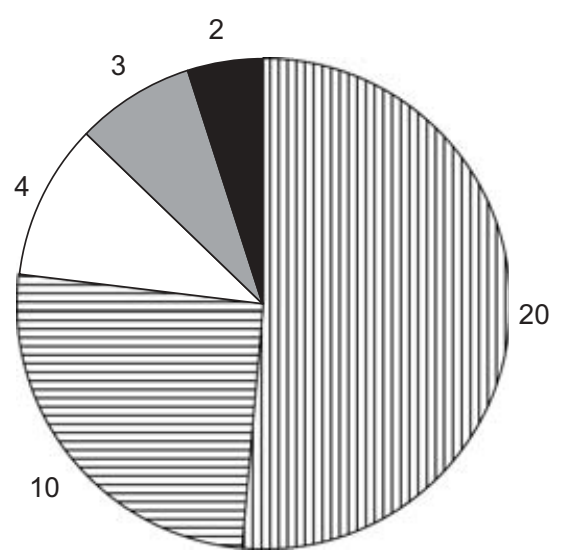

Fig. 1 Number of articles ( $n$ 39) assessed with the Tabloid Analysis Tool by origin (匹, Daily Mail; $\Xi$, Daily Express; $\square$, The Sun; $\square$, Daily Star, $\mathbf{\square}$, Daily Mirror)

headlines that were inconsistent and therefore deemed inaccurate with respect to the original research, e.g.

Headline: 'Nuts: Better for you than fruit?'

Research: Polyphenolic content and sensory properties of normal and high oleic acid peanuts

Nineteen articles attributed information to the research that could not be found within the original manuscript.

\section{Balance}

Twenty-five articles selectively reported the original research results. Thirty-six gave no mention of research limitations. Five articles provided a third party quote/ comment on the research reported, while six made specific statements that were not qualified by a valid professional/academic source.

\section{Context}

One article quoted a registered dietitian and one quoted a nutritionist (though not identified as registered). Five articles stated the name of an organisation or suggested seeking further information from a health/medical professional. Twenty-two articles reported preliminary studies and did not explain how the results related to practical nutrition and dietary recommendations.

\section{Attitudes}

Two focus groups were conducted, each with eight participants. The focus group data are illustrated as key themes that emerged within the three recognised domains of attitude formation (Fig. 2).

Some differences in participant comprehension were observed. There was widespread agreement in both groups that the information was potentially misleading, but not necessarily inaccurate. Participants' feelings were largely negative, although several agreed there is value in newspapers reporting nutrition information. Participants' intentions to act on the information were negligible, 


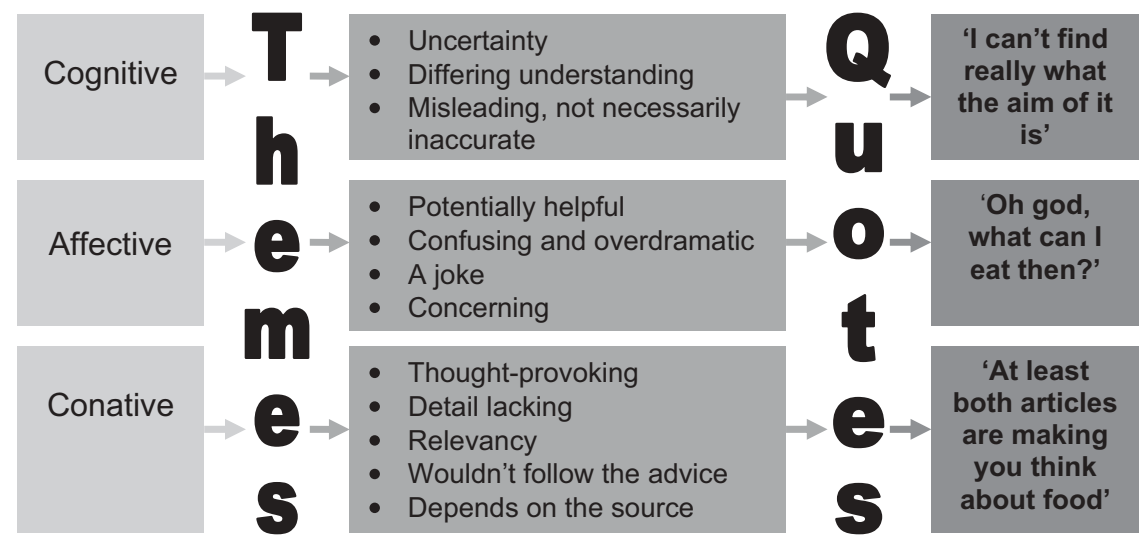

Fig. 2 Attitudes expressed by the focus group participants

due to a lack of conviction regarding the material, its source, or lack of individual applicability. The articles carried some interest for participants, but mainly as general interest.

\section{Discussion}

The present study supports the perception that tabloids are sensationalistic to the point whereby the information given is rarely balanced or sufficiently contextualised to be of practical or evidenced use. The majority of research results were reported inaccurately, and headlines were inconsistent with the true nature of the original research reported. This challenges journalistic ethical responsibility outlined by Keeble ${ }^{(31)}$, and supports arguments which uphold that media coverage of medical science is characterised by inaccuracies ${ }^{(9,32)}$.

Opinions within the literature suggest the public is confused by the media's portrayal of health messages $^{(10,18)}$. Public attitudes towards the reporting of nutrition research observed in the present study were not particularly favourable. Focus group participants expressed uncertainty in their understanding of the tabloid articles; an unsurprising finding given that analysis from the TAT highlighted deficiencies in the provision of practical context.

In contrast to the findings from the TAT, focus group participants did not question or mistrust the factual accuracy of the information presented, although they did believe information could be presented misleadingly. Some value was expressed towards the provision of nutrition information via the print media, but dramatic headlines and sensationalism clearly limited the application of this information beyond a point of general interest. The relationship between the three attitudinal domains was widely apparent, supporting findings within the literature $^{(18)}$ that those who express confusion or negative feelings towards media articles are most likely to disregard them.
Although the majority of research reported in the tabloids was preliminary and not conclusive, focus group members did not appear to comprehend the evolving nature of research. Expression of the conditional nature of most research findings is perhaps incompatible with the tabloid disposition to print sensational certainties. Newspapers are not medical journals, but journalists could employ simple measures to aid the public's comprehension here.

Data generated from the TAT and focus groups identified a lack of practical dietary guidance. Dietitians and other expert third-party sources were poorly utilised, and could have added valuable context. The IFIC and IFT ${ }^{(12)}$ recommend journalists translate the latest nutrition research into what is on the public's dinner plate, a fundamental skill practised by all dietitians. Providing context in reports may be limited by available column inches; however, journalists could signpost to relevant organisations/health professionals.

A limitation of the present study was that it did not distinguish whether journalists base their reports on original research manuscripts or press releases. Journalists are encouraged to obtain the full manuscript ${ }^{(33)}$, as press releases are noted to fail in reporting study limitations and exaggerate study findings ${ }^{(34)}$. Although this information may have been helpful in appreciating where inaccuracies occurred, it does not diminish the key findings of the study. The data collection period for the tabloid articles coincided with a global disaster, which may have reduced the volume of reporting related to this topic area. A further limitation of the present study was that it did not explore possible diversity in readership between 'mid-market' and 'red top' tabloids. The articles obtained were largely from 'mid-market' tabloids, noted to have readership from a wide spread of social classes; however 'red top' tabloids have a greater proportion of readers from the lower social classes ${ }^{(29)}$.

Within the qualitative literature there is no numerical consensus regarding how many focus groups are required to make data viable ${ }^{(25)}$. The multi-method nature 
of the present research, available time and resources restricted the number of focus groups run; however the key themes that emerged were widely evident in both groups, indicating that a saturation point was reached ${ }^{(27)}$.

The present study highlights cause for concern regarding the quality of tabloid reporting on nutrition research. Furthermore, it illustrates that attitudes expressed by members of the public are not favourable. There is some value attached to newspapers providing nutrition information; inferring that efforts to more effectively use this media would not be in vain.

The British Dietetic Association recently launched a media 'hotline' for journalists and a 'hot topics' section on its website. Both will strengthen links between dietitians and the media. However, the present study shows that best practice guidelines need be developed for the British press to improve the quality of reporting on emerging nutrition research.

\section{Conclusion}

Tabloid newspapers are a popular form of mass media in the UK, offering a significant opportunity to reach the wider public with key nutrition and health messages ${ }^{(35)}$. The present study highlights that the current quality of reporting nutrition research is inadequate, and public attitudes towards it are not favourable. Despite these criticisms, members of the public believed there is value in newspapers conveying such information, inferring that future opportunities to more effectively use this medium are worthy of attention.

There is a missed opportunity in tabloid reporting to give authentic dietary advice to the public. Registered dietitians could be more readily accessed by journalists to comment on the intended public release of controversial dietary findings.

The present article describes an exploratory study and clearly the research questions should be investigated on a larger and more representative sample. The TAT has proved to be a functional tool and could be used to examine, for example, other UK newspapers (broadsheets) to explore whether similar inaccuracies exist there.

The motivations and competencies of journalists are under-researched. A research question worthy of exploration would be 'Are journalists who are tasked with reporting scientific research sufficiently knowledgeable/ trained to précis and represent scientific articles?' Public responses to sensational and inaccurate reporting could be explored on a more representative sample through a questionnaire survey.

\section{Acknowledgements}

There are no conflicts of interest. The Food Standards Agency Wales kindly funded book vouchers as incentives to encourage focus group participant attendance. The first author wishes to acknowledge Professor Hogard for her guidance as supervisor for the study, and also the North East Wales NHS Trust Dietetics Department for their support and allocation of employment time to undertake this research.

\section{References}

1. Ayoob T, Duyff RL \& Quagliani D (2002) Position of the American Dietetic Association: Food and nutrition misinformation. JAMA 102, 260-266.

2. Grilli R, Ramsay C \& Minozzi S (2005) Mass media interventions: effects on health services utilisation (review). The Cochrane Database of Systematic Reviews 2005, issue 2, CD000389. http://www.mrw.interscience.wiley.com/ cochrane/clsysrev/articles/CD000389/frame.htm

3. Holgardo B, Martinez-Gonzalez MA, De Irala-Estevez J, Gibney M, Kearney J \& Martinez JA (2000) Sources of information about diet and health in a Mediterranean country. Eur J Public Health 10, 185-191.

4. Alden C (editor) (2005) Media Directory 2005. London: Guardian Books.

5. Food Standards Agency (2005) Consumer attitudes to food standards 2004. http://www.food.gov.uk/mulitmedia/ pdfs/casuk04.pdf (accessed May 2005).

6. Bubela TM \& Caulfield TA (2004) Do the print media 'hype' genetic research? A comparison of newspaper stories and peer-reviewed research papers. CMAJ 170, 1399-1407.

7. Henderson L, Kitzinger J \& Green J (2000) Representing infant feeding: content analysis of British media portrayals of bottle feeding and breast feeding. BMJ 321, 1196-1198.

8. Philo G, Secker J, Platt S, Henderson L, McLaughlin G \& Burnside J (1994) The impact of the mass media on public images of mental illness: media content and audience belief. Health Educ J 53, 271-281.

9. Stryker JE (2002) Reporting medical information: effects of press releases and newsworthiness on medical journal articles' visibility in the news media. Prev Med 35, 519-530.

10. McBean LD (2001) Good science: its role in setting the record straight. Dairy Council Digest 72(5), 25-30.

11. Wellman NS, Scarbrough FE, Ziegler RG \& Lyle B (1999) Do we facilitate the scientific press and the development of dietary guidance when findings from single studies are published? An American Society for Nutritional Sciences Controversy Session Report. Am J Clin Nutr 70, 802-805.

12. International Food Information Council Foundation \& Institute of Food Technologists (2005) Guidelines for communicating the emerging science of dietary components for health. http://ific.org/nutrition/functional/guide lines/upload/FFGuidelnsBro.pdf (accessed May 2005).

13. Social Issues Research Centre, The Royal Society \& The Royal Institute of Great Britain (2001) Guidelines on science and health communication. http://www.sirc.org/ publik/revised_guidelines.shtml (accessed February 2005).

14. Borra ST, Earl R \& Hogan EH (1998) Paucity of nutrition and food safety 'news you can use' reveals opportunity for dietetics practitioners. J Am Diet Assoc 98, 190-193.

15. Sihota S \& Lennard L (2004) Health Literacy: Being Able to Make the Most of Health. London: National Consumer Council.

16. Albery IP (2004) Social psychology. In Complete Psychology pp. 362-449 [G Davey, editor]. London: Hodder \& Stoughton.

17. Reah D (2002) The Language of Newspapers, 2nd ed. London: Routledge. 
18. Patterson RE, Satia JA, Kristal AR, Neuhouser ML \& Drewnowski A (2001) Is there a consumer backlash against the diet and health message? J Am Diet Assoc 101, 37-41.

19. Ward SJA (2005) Journalism ethics from the public's point of view. Journalism Stud 6, 315-330.

20. Frewer LJ, Scholderer J \& Bredahl L (2003) Communicating about the risks and benefits of genetically modified foods: the mediating role of the trust. Risk Anal 23, 1117-1132.

21. Russell G (1999) Essential Psychology for Nurses and Other Health Professionals. London: Routledge.

22. Goldberg JP (1997) Nutrition research in the media: the challenge facing scientists. J Am Coll Nutr 16, 544-550.

23. Harvard School of Public Health \& International Food Information Council Foundation (1998) Improving public understanding: guidelines for communicating emerging science on nutrition, food safety and health. J Natl Cancer Inst 90, 194-199.

24. Hackman EM \& Moe GL (1999) Evaluation of newspaper reports of nutrition-related research. J Am Diet Assoc 99, 1564-1566.

25. Gibbs A (1997) Focus groups. Social Research Update. http://www.soc.surrey.ac.uk/sru/SRU19.html (accessed July 2005).
26. Morgan DL (1998) The Focus Group Guidebook. Focus Group Kit 1. Thousand Oaks, CA: Sage.

27. Krueger RA \& Casey MA (2002) Focus Groups. A Practical Guide for Applied Research, 3rd ed. Thousand Oaks, CA: Sage.

28. Bell E \& Alden C (2003) Media Directory 2004. London: Guardian Books.

29. Duffy B, Rowden L (2005) You are what you read? How newspaper readership is related to views. http:// www.mori.com/polls/2004/newspaper-readership.shtml (accessed June 2005).

30. Litosseliti L (2003) Using Focus Groups in Research. London: Continuum.

31. Keeble R (2001) Ethics for Journalists. London: Routledge.

32. Condit C (2004) Science reporting to the public: does the message get twisted? CMAJ 170, 1415-1416.

33. Entwistle V (1995) Reporting research in medical journals and newspapers. BMJ 310, 920-923.

34. Woloshin S \& Schwartz LM (2002) Press releases translating research into news. JAMA 287, 2856-2858.

35. Whitehead D (2000) Using mass media within healthpromoting practice: a nursing perspective. J Adv Nurs $\mathbf{3 2}$, 807-816. 
Appendix - Tabloid Analysis Tool (TAT)

RESEARCH NUMBER

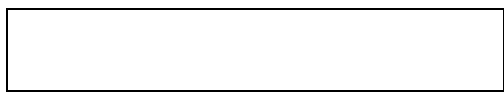

ARTICLE HEADLINE

Newspaper \& date

TITLE OF CORRESPONDING RESEARCH PAPER

Journal \& date of publication

\section{RESEARCH PAPER}

Empirical study

( )

Editorial/Commentary

\begin{tabular}{c}
\hline $\begin{array}{c}\text { Journal \& date of } \\
\text { publication }\end{array}$ \\
\end{tabular}

RESEARCH SOURCE GIVEN (TICK ALL THAT APPLY)

$\begin{array}{ll}\text { Journal } & (\text { ) } \\ \text { Author } & (\text { ) } \\ \text { Organisation } & (\text { ) }\end{array}$

ARTICLE SIZE

Small

(less than half a page)

Medium

(half a page)

Large

(over half a page-whole page and/or front page coverage)

\section{COLUMN INCHES}

NEWSPAPER PAGE NUMBER

TOTAL No. OF STUDIES MENTIONED IN THE ARTICLE 
(1) Aim of the study reported?

Yes

No

(2a) Sample size reported?

Yes

No

(2b) Reported accurately?

Yes

No

(3a) Study population reported?

Yes No

(3b) Characteristics of the population reported fully?

Yes

No

(4) Study design stated or described?

Yes

No

(5) Method of data collection reported?

Yes

No

(6) Method of data analysis reported?

Yes

No

(7a) Study results reported accurately?

Yes

No

(7b) Only selected results reported?

Yes

No

(8) Study conclusions reported?

Yes No

(9) Limitations of the study reported?

Yes

No
(10) Headline consistent with research findings?

Yes

No

(11) Any information attributed to the published research study that cannot be found?

Yes

No

(12) Quote from expert third-party source(s), i.e. not related to the research?

Yes

No

(13) Dietitian or registered nutritionist quoted in the article?

Yes

No

(14) Any statements attributed to 'experts', 'researchers' or 'studies' that are unsubstantiated?

Yes

No

(15) Is a credible source (other than the journal article), i.e. helpline, support organisation, website or GP/ health professional, suggested for readers wanting further information?

Yes

No

(16) For studies focusing on a specific nutrient, are foods/foodstuffs identified where it may be found?

Yes

No

$\mathbf{N} / \mathbf{A}$

(17a) Is the quantity of food/ nutrient linked to the health outcome reported?

Yes

No

$\mathbf{N} / \mathbf{A}$

(17b) Would the average adult/relevant population group be reasonably expected/advised to consume this amount?

Yes

No

N/A 